\title{
Primary Breast Lymphoma - A Case Report
}

Dr. D. Manimala ${ }^{1 *}$, Dr. E. Kiran Kumar ${ }^{2}$, Dr. K. Varun ${ }^{3}$, Dr. G. Aswini ${ }^{4}$

\author{
${ }^{1,3,4}$ Assistant Professor, ${ }^{2}$ Prof and HOD, Department of Pathology, Gayatri Vidya Parishad Institute of Health Care and Medical Technology, \\ Marikavalasa, Vishakapatnam, India
}

Primary breast lymphoma (PBL) is a unique clinical entity accounting for $0.4-0.5 \%$ of all neoplasms in breast. The clinical features and imaging findings in breast lymphoma are nonspecific, difficult to differentiate from breast carcinoma. It can develop in both gender, but is predominantly reported among female patients and is very rare finding in males. Most of the cases present in the $5^{\text {th }}$ or $6^{\text {th }}$ decade of life. Usually unilateral, around $10 \%$ patients may have bilateral presentation. We report a rare case of Primary breast lymphoma which was diagnosed and confirmed by histopathology and immunohistochemistry.

Keywords: Primary breast lymphoma,diffuse large B cell lymphoma.

Copyright @ 2020: This is an open-access article distributed under the terms of the Creative Commons Attribution license which permits unrestricted use, distribution, and reproduction in any medium for non-commercial use (NonCommercial, or CC-BY-NC) provided the original author and source are credited.

\section{INTRODUCTION}

Breast lymphoma is a rare entity. It is classified into twotypes, primary and secondary [1]. It can occur as a primary breast tumour or as an extranodal manifestation of a systemic disease [2]. Primary breast lymphoma accounts for 0.4 to $0.5 \%$ of all breast malignancies, 0.38 to $0.7 \%$ of all lymphomas and 1.7 to $2.2 \%$ of all extranodal lymphomas [3, 4]. It most commonly affects females and few cases were reported in males [9]. The age group affected is 31-81 years. It usually has unilateral presentation and bilateral involvement was seen in younger women [4].

\section{Case Report}

A 50 year old female presented with right breast lump of 3 months duration. The lump was rapidly increasing in size and was associated with pain. Patient had history of intermittent low grade fever. There is history of loss of appetite and weight. She is a known case of hypertension and Type 2 diabetes mellitus on medications. There is no past history of TB contact or prior surgery. She is married and has four children. She attained menopause at the age of 47 years. There is no significant family history for malignancy.

On general examination patient was pale and cachetic. There was no generalized lymphadenopathy. Her vitals were stable. On clinical examination right breast was diffusely enlarged. Skin over the breast was shiny. There was slight nipple retraction but no nipple discharge. On palpation, $8 \times 8 \mathrm{~cm}$ firm mobile mass was noted occupying entire breast. Her left breast appeared normal. Lab investigations revealed moderate degree of microcytichypochromicanemia with total and differential WBC counts within normal limits. Her CRP was $28 \mathrm{IU} / \mathrm{L}$ and ESR was $42 \mathrm{~mm} / 1^{\text {st }}$ hour. Ultrasound imaging was done which showed diffuse fibroglandularedema accompanied by subcutaneous edema at subareolar region and inner quadrant of right breast. There were also a few enlarged deep seated lymphnodes in the right axillary region. A probable diagnosis of neoplasticetiology was made based on imaging.

\begin{tabular}{llr}
\multicolumn{2}{c}{ FNAC } & smears from the breast mass showed \\
moderate & cellularity & comprising
\end{tabular} dissociatedmonomorphic cells, probably atypical lymphoid cells with high nuclear cytoplasmic ratio and irregular nuclear membrane. On the basis of cytological features, the probable diagnosis was lymphoproliferative disorder. We received a simple mastectomy specimen measuring $12 \times 7 \times 6 \mathrm{~cm}$, cut section of which showed a well circumscribed mass measuring $10 \times 5 \mathrm{~cm}$, tan white with focal yellow and gray brown areas. Biopsy showed diffuse infiltrating sheets of neoplastic cells with coarse chromatin, prominent nucleoli and scant cytoplasm. Extensive areas of necrosis, infiltration into adjacent adipose tissue and skeletal muscle were noted.All excision margins were positive. There was neither involvement of nipple nor evidence of lymphovascular invasion and perineural invasion noted. Immunohistochemical 
staining was performed. The tumour cells were negative for cytokeratin, synaptophysin and GATA 3, positive for CD45. CD20, CD 79a and BCL2 positive. CD 3 was negative. The proliferative index KI 67 was positive in 40 to $50 \%$ cells. A final diagnosis of Primary Breast Lymphoma -Diffuse large B cell phenotype was made. CT chest, abdomen, pelvis failed to demonstrate other sites of disease.

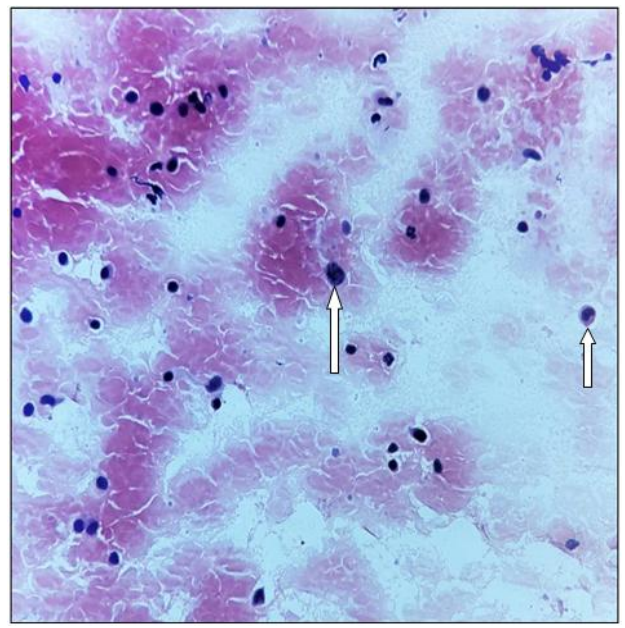

Fig-1: FNAC smears showing few atypical lymphoid cells with irregular nuclear margins.

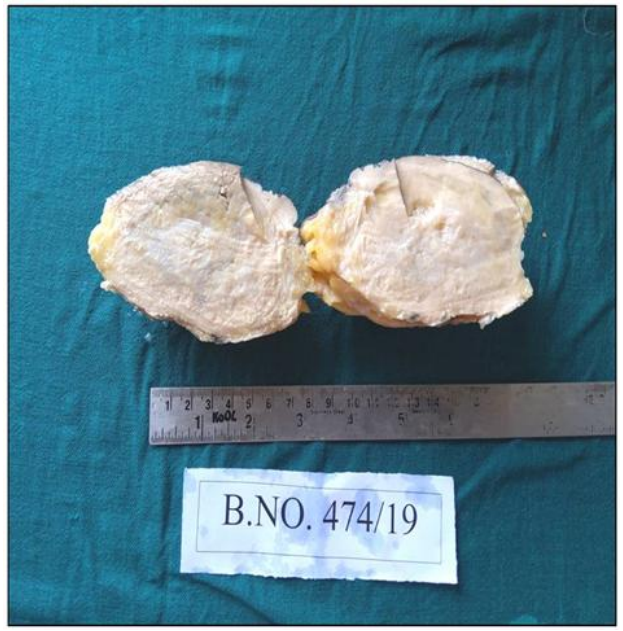

Fig-2: Simple mastectomy specimen cut section - solid, tan white tumour

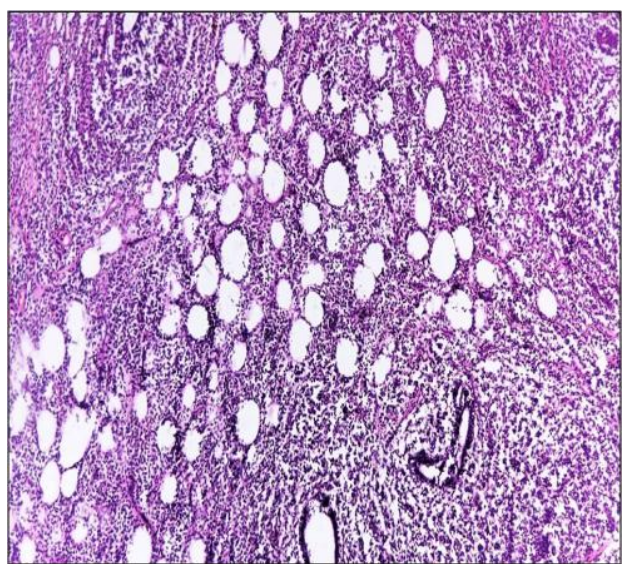

Fig-3: $H$ and $E$ 10xdiffuse\&dense infiltration of neoplastic cells

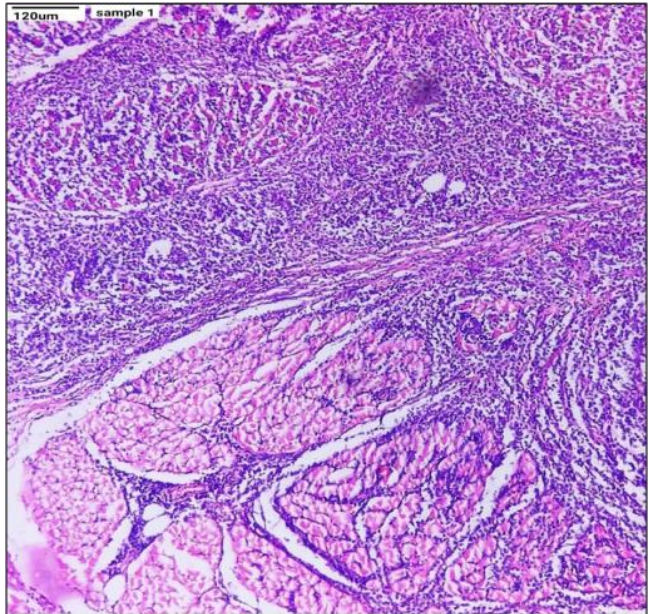

Fig-4: $H$ and $E$ 10x infiltration of underlying muscle by neoplastic lymphoid cells

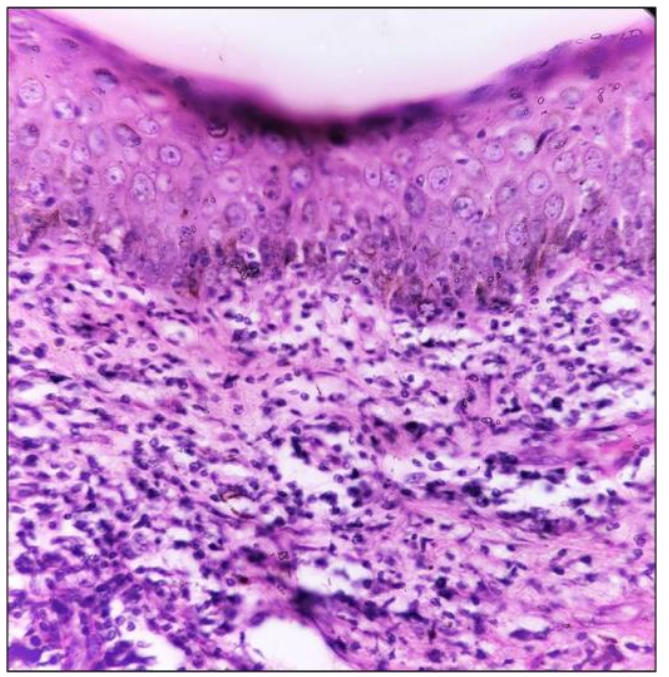

Fig-5: $H$ and $E$ 40x infiltration of neoplastic cells into the epidermis

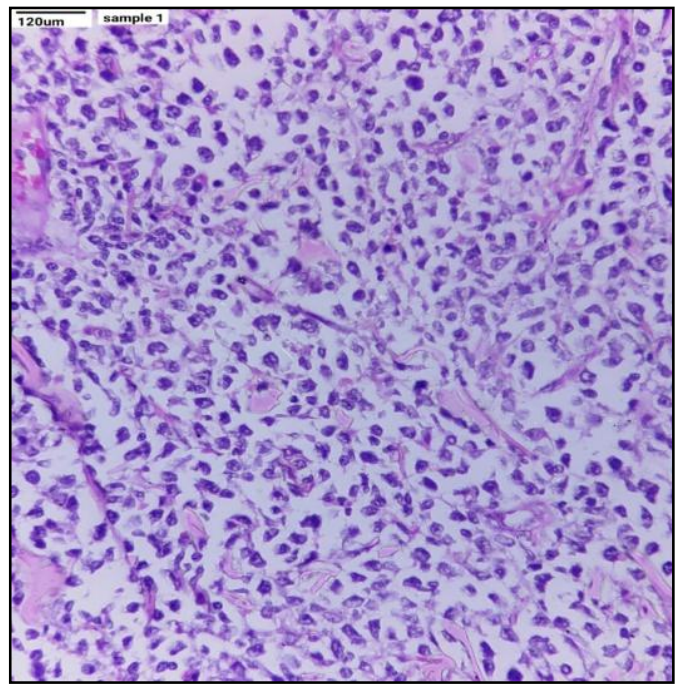

Fig-4: $\mathrm{H}$ and $\mathrm{E}$ 40xmedium-large sized cells with coarse chromatin and scant cytoplasm 


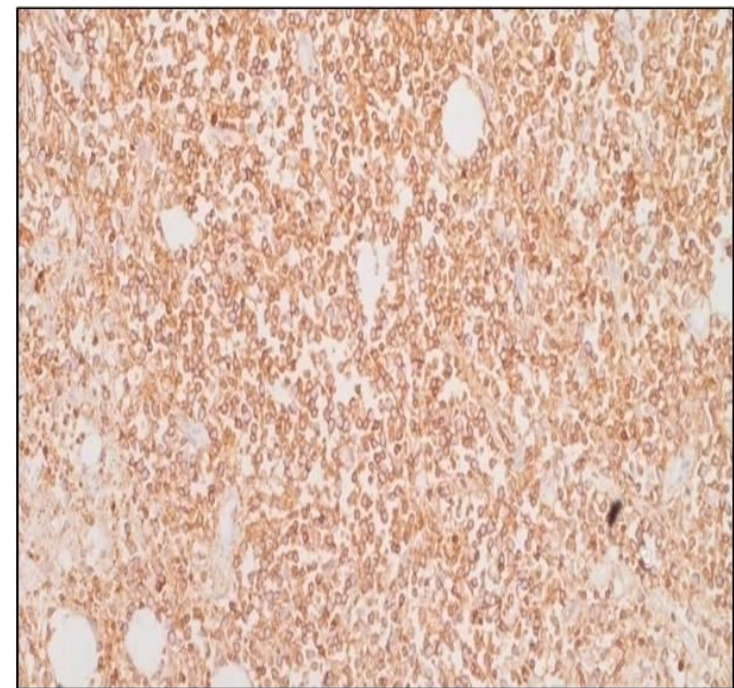

Fig-7: Immunostain CD 45 Positive

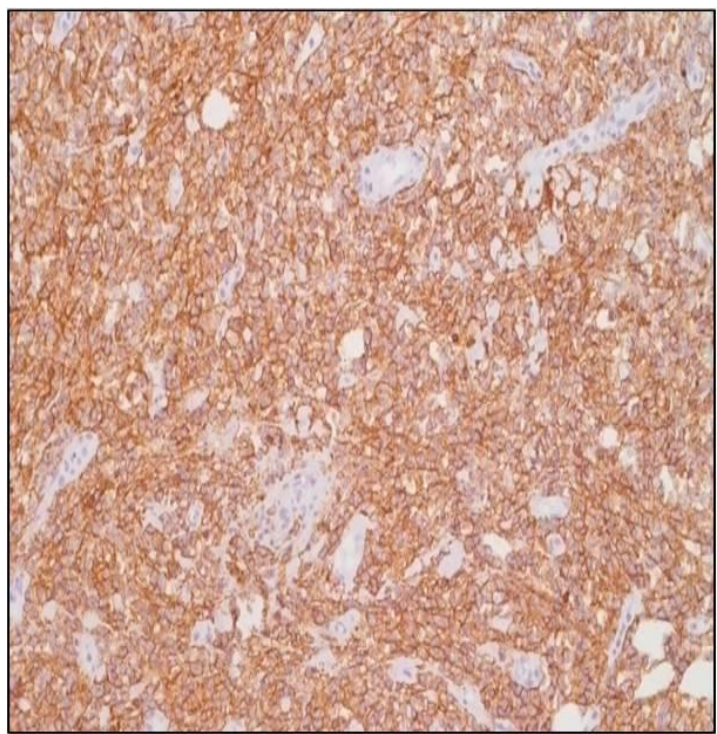

Fig-8: ImmunostainCD 20 Positive

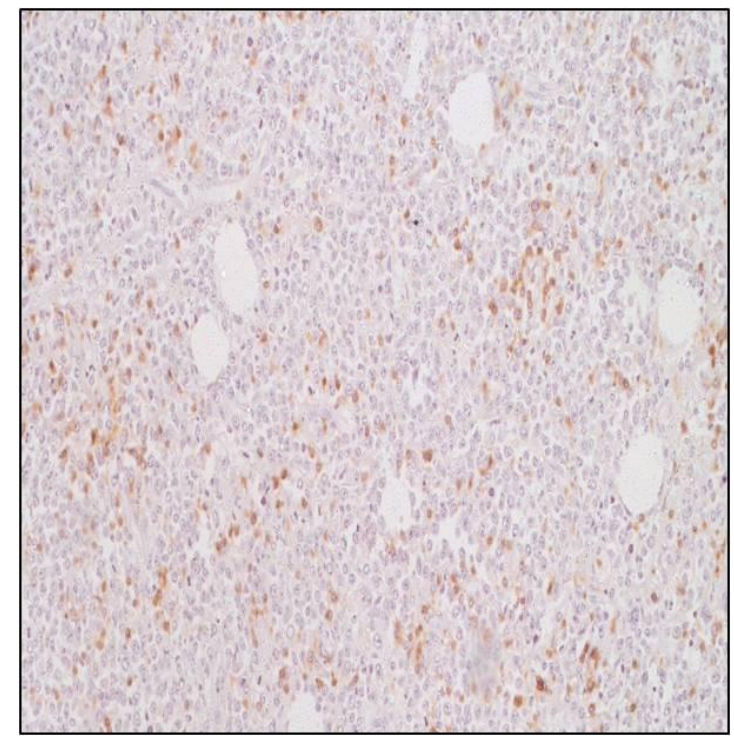

Fig-9: Immunostain CD 3 Negative

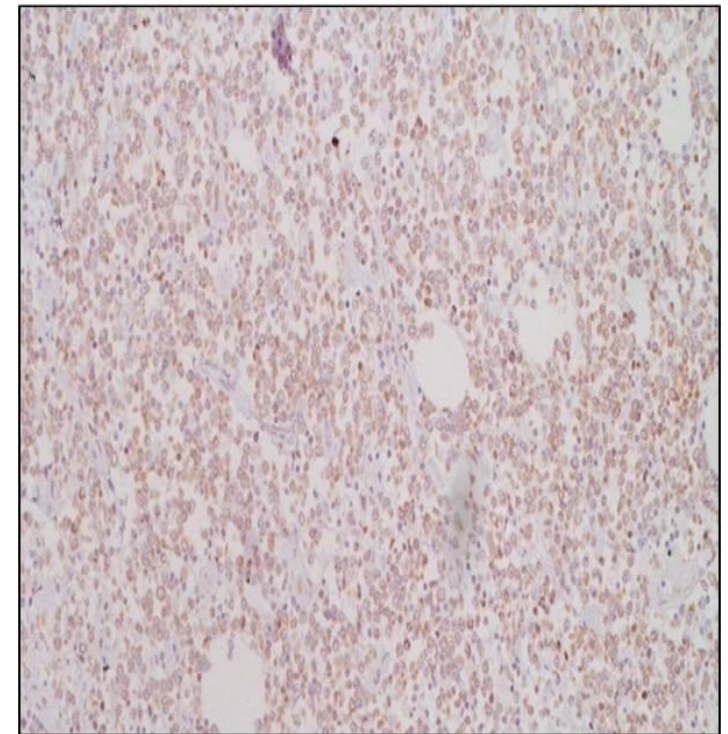

Fig-10: Immunostain CD79a Positive

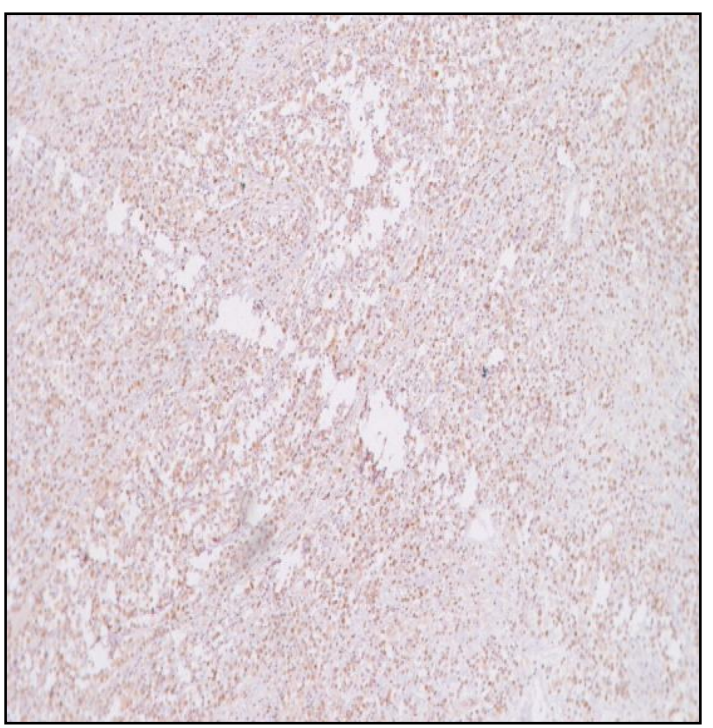

Fig-11: Immunostainbcl 2 positive

\section{DISCUSSION}

Breast lymphoma is a rare entity. The rarity is accounted to the little lymphoid tissue in the breast [2, 3]. Primary lymphoma of the breast (PBL)is defined as the tumor confined to the breast with or without ipsilateralaxillary lymph node metastases [6]. Ipsilateralaxillarylymphode involvement is shown in more than $40 \%$ of patients with PBL [2]. Weisman and Liao in 1972 defined the diagnostic criteria for PBL [7]:

i. The clinical site of presentation is the breast

ii. ii) previous history of lymphoma or evidence of wide spread disease is absent at the time of diagnosis

iii. lymphoma is demonstrated in close association with breast tissue in the pathological specimen

iv. iv) Ipsilateral lymph node involvement if they develop simultaneously with the primary breast tumor[7]. 
Breast lymphoma can develop in both gender, but is predominantly (98\%) reported among female patients and is very rare finding in males [8]. Most cases present in the 5th or 6th decade of life [8]. The present case was diagnosed with PBL in the fifth decade; the peak age for PBL is usually the sixth decade. The peak age of PBL is different between ethnicities with median age in Western countries is over sixty years (62-64 years), whereas the median age in East Asian countries(45-53 years) is a decade lower[5]. Unilateral breast involvement is more common, particularly in the upper quadrant of the right side[9] although bilateral involvement has been reported in 1-14\% of cases [8]. The right breast was involved in our case. PBL occurs more frequently in the right breast, with a 3:2 ratio[5]. Although its etiologyis not much known,its association with estrogen exposure and autoimmune diseases has been illustrated [3].

The clinical features and imaging findings in breast lymphoma are nonspecific, difficult to differentiate from breast carcinoma [1]. The most common presenting symptom is enlarging, painless breast mass. According to the literature pain has been reported to occur in $4-25 \%$ of patients [2]. Signs of nipple or skin involvement are infrequent [8] and systemic symptoms such as sweating, weight loss and fever, are infrequent, and have been reported to occur in roughly around $8-9 \%$ of the reported cases [2]. It has been reported that high-grade lymphomas commonly manifest as diffuse breast enlargement, whereas low and intermediate-grade tumors often have nodular patterns [9].

Primary breast lymphoma are mostly Non Hodgkins B cell type (94\%) with Diffuse large B cell lymphoma being the most common type accounting for 40 to $70 \%$ cases[1]. The other frequent histological types are follicular lymphoma (15\%), mucosa associated lymphoid tissue lymphoma (12.2\%), Burkitt's lymphoma, and Burkitt-like lymphoma [5], which is typically associated with pregnancy [3]. In this case report, we performed not only aspiration cytology but also excisional biopsy, and the histopathological examination showed diffuse infiltration of monotonus appearing lymphoid cells, which were predominantly positive for CD20, CD79a and BCL 2markers and was consistent with diffuse large B cell lymphoma.

Several studies have recommended that surgery should be minimally invasive for diagnostic purpose because extensive surgery may carry a high risk of morbidity. Axillary clearance has no therapeutic advantage [9]. The main stay of treatment is chemotherapy and radiotherapy as these are highly sensitive to both [6]. Prognosis of patients with breast lymphoma can range from 26 and $66 \%$ for 5 year survivalrates[6].

\section{Conclusion}

We report a rare case of Primary Breast Lymphoma -B cell type, involving the right breast.Treatment of Breast lymphoma differs much from breast carcinoma. An early and accurate histological diagnosis is essential to select the best management and avoid major surgical intervention.

\section{REFERENCES}

1. Taron J, Fleischer S, Bahrs S, Preibsch H, Hattermann V. Secondary Breast Lymphoma: A Case Report. Arch Hematol Case Rep Rev. 2017;2(2):019-21.

2. Surov A, Holzhausen HJ, Wienke A, Schmidt J, Thomssen C, Arnold D, Ruschke K, Spielmann RP. Primary and secondary breast lymphoma: prevalence, clinical signs and radiological features. The British journal of radiology. 2012 Jun;85(1014):e195-205.

3. Nisar U, Khan M, Nisar S, Khan S. Primary Breast Lymphoma with Unconventional Presentation: A Case Report. J Leuk. 2017;5(238):2.

4. Pandure M, Karle R, Dongre S, Baviskar B. Primary non-Hodgkin's lymphoma of the breast: a case report. Internet Journal of Medical UpdateEJOURNAL. 2013;8(1).

5. Lee KC, Lee SH, Sung K, Ahn SH, Choi J, Lee SH, Lee JH, Hong J, Park SH. A case of primary breast diffuse large B-cell lymphoma treated with chemotherapy followed by elective field radiation therapy: a brief treatment pattern review from a radiation oncologist's point of view. Case reports in oncological medicine. 2015;2015.

6. Anne N, Pallapothu R. Lymphoma of the breast: a mimic of inflammatory breast cancer. World journal of surgical oncology. 2011 Dec;9(1):125.

7. Mohamed KE, Ali RA. Primary breast lymphoma: a case report and review of the literature. Clinics and practice. 2017 Jun 7;7(3).

8. Orlandi A, Sanchez AM, Calegari MA, D'Archi S, Santoro A, Di Leone A, Mulè A, Arena V, Masetti R, Barone C, Franceschini G. Diagnosis and management of breast lymphoma: a singleinstitution retrospective analysis.

9. Jabbour G, El-Mabrok G, Al-Thani H, El-Menyar A, Al Hijji I, Napaki S. Primary breast lymphoma in a woman: a case report and review of the literature. The American journal of case reports. 2016;17:97. 